\title{
Incidence of Traumatic Injection Neuritis among Children $<15$ Years Old in Yemen
}

\author{
Abdulrahman Sallam Al-Kubati' ${ }^{1}$, Hadi Mohammed Mujlli², Zumurudah Taha Haroon' \\ ${ }^{1}$ Neurology Department, Medical College, Sana'a University, Sana'a, Yemen \\ ${ }^{2}$ Medical Department, Medical College, Thamar University, Dhamar, Yemen \\ Email: Neuroepileptic.center@gmail.com,dr.hadimujlli@gmail.com,dr.zumurudah@hotmail.com
}

How to cite this paper: Al-Kubati, A.S. Mujlli, H.M. and Haroon, Z.T. (2017) Incidence of Traumatic Injection Neuritis among Children $<15$ Years Old in Yemen. Open Access Library Journal, 4: e3221. http://dx.doi.org/10.4236/oalib.1103221

Received: December 10, 2016

Accepted: January 19, 2017

Published: January 22, 2017

Copyright (C) 2017 by authors and Open Access Library Inc.

This work is licensed under the Creative Commons Attribution International License (CC BY 4.0).

http://creativecommons.org/licenses/by/4.0/

\section{Open Access}

\begin{abstract}
Background: Traumatic Injection Neuropathy (TIN) can occur because of unsafe intramuscular injection practices. TIN presents as acute peripheral neuropathy with flaccid paralysis of the injected limb within 24 hours after injection and is associated with pain and hypothermia in the affected limbs. This complication is of particular concern in countries with high rates of unnecessary injections. Objective: The main objectives were to determine the incidence of Traumatic Injection Neuropathy (TIN) and hospital outcome of patients within 60 days of admission. Material \& Methods: The records of all patients followed with flaccid paralysis through the WHO program for Acute Flaccid Paralysis (AFP), concerning eradication of poliomyelitis with the differential diagnosis including TIN in governorates in Yemen. From 1 January 2010 to 31 December 2015 were reviewed. Those patients suspected to be TIN were examined by a neurologist and pediatric consultant to confirm the diagnosis. At the time of admission, specific form was designed to record demographic characteristics, clinical finding and presentation of paralysis. All patients follow up for 60 days. Results: During the study period, 788 patients were diagnosed as TIN. Of these 529 (67.1\%) were males and $295(32.9 \%)$ were females. The age of the patients was ranged (between 1 to 15 years), and most of them 555 (70.4\%) were young children of $\leq 5$ years old and 233 (29.5\%) cases were 5 - 15 years old. The overall incidence was $28 / 100,000$ population. The outcome of patients showed that 354 (44.9\%) had residual paralysis. 429 (54.4\%) TIN patients improved, and 3 (0.4\%) were lost, and 2 $(0.3 \%)$ patients died within 60 days of follow-up. Conclusion: This study confirms that traumatic injection neuritis is the second most common cause of Acute Flaccid Paralysis in Yemen after Guillain-Barré Syndrome with high morbidity in children.
\end{abstract}

\section{Subject Areas}

Pediatrics, Public Health 


\section{Keywords}

Traumatic Injection Neuritis, Children, Yemen

\section{Introduction}

The World Health Organization (WHO) in 1999 reported that out of the $8-12$ billion injections administered worldwide annually, the vast majority (90\% 95\%) are for therapeutic purposes, and 50 percent are unsafe, and 75 percent are unnecessary. Injection administration is seen as one of the most common healthcare procedures, and unsafe injections are associated with morbidity and mortality, especially in developing countries [1] [2] [3].

Traumatic Injection Neuropathy (TIN) can occur because of unsafe intramuscular injection practices. TIN involving the sciatic and radial nerves presents as acute peripheral neuropathy with flaccid paralysis of the injected limb within 24 hours after injection and is associated with pain and hypothermia in the affected limbs [4] [5] [6].

This complication is of particular concern in countries with high rates of unnecessary injections [2].

While some data exist regarding the medical complications of these injections, no estimate has been published regarding the disease burden caused directly by injection trauma [5].

Affected individuals usually present with foot drop and this can result in varying degrees of motor disability depending on the timing and duration of corrective measures instituted [7].

In Yemen, all acute flaccid paralytic conditions are reported to the Acute Flaccid Paralysis (AFP) surveillance system of the poliomyelitis eradication initiative. The AFP surveillance system has achieved or exceeded global targets for quality and sensitivity since 2000 .

This study was a review of AFP surveillance data to identify the incidence of TIN in Yemen and to describe the basic epidemiology of the disease.

\section{Methods and Materials}

The records of retrospective patients followed with Acute Flaccid Paralysis (AFP) through the WHO program in the Ministry of health of Yemen. Approval was obtained through a local committee of AFP program prior to the commencement of the study, and that informed patient consent was received from all study participants. We searched the case records of AFP surveillance data collected between 1 January 2010 and 31 December 2015 to identify potential cases of Traumatic Injection Neuritis (TIN). The data collected concerning eradication of poliomyelitis with the differential diagnosis including (TIN) in Yemen. The TIN was clinically diagnosed by neurologist and pediatrics consultation. The clinical and demographic characteristics, including age, gender, pre- 
ceding events, presentation of paralysis of the lower limb Left or Right at the time of examination with 60 days follow up for each case by health team workers in each governorate.

The diagnosis is confirmed on the basis of clinical presentation by examination of neurologist or pediatric consultant in each governorate. A structured questionnaire was designed which documented age of the patient, sex and its distributions concerning TIN residual cases, non-residual cases and died or lost cases in these governorates.

Epi info statistical method was used for analysis of data.

\section{Results}

Demographical and clinical features:

Of 788 TIN patients, there were 529 male (67.1\%) and 259 female (32.9\%) patients, as shown in Figure 1.

There were $555(70.4 \%)$ patients under the age 5 years, patients ranging from 5 to 15 years 233 (29.5\%), as shown in Table 1, Figure 2 and Figure 3.

Patients characteristic of paralysis with follow up after 60 days, 429 (54.4\%) TIN patients non residual (improved) and 354 (44.9\%) residual (not improved) all Governorates in Yemen, as shown in Figure 4.

\section{Discussion}

Injection-related traumatic neuropathy often results in life-long disability [6].

As we progress towards WHO eradication of poliomyelitis, causes of Acute Flaccid Paralysis other than polio, we found Traumatic Injection Neuritis (TIN)

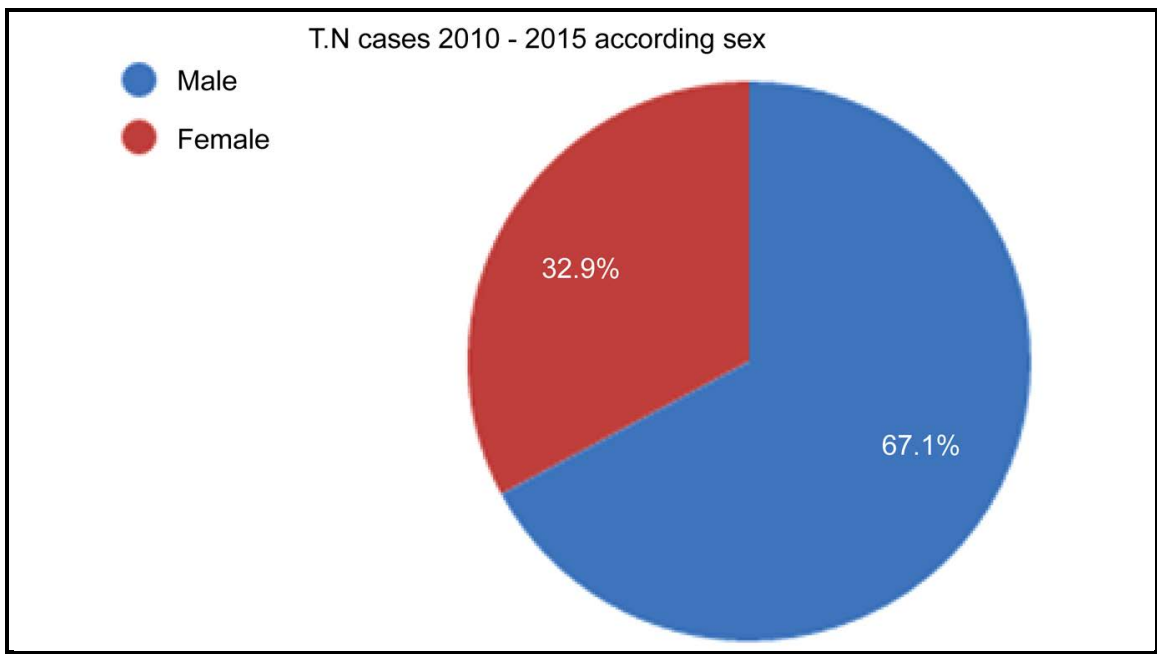

Figure 1. The percentage of TIN Male and Female from 2010 to 2015.

Table 1. TIN percentage according to age in all Governorates of Yemen from 2010-2015.

\begin{tabular}{|c|ccc|cccc|}
\hline Year & $2010 \mathrm{Y}$ & $2011 \mathrm{Y}$ & $2012 \mathrm{Y}$ & $2013 \mathrm{Y}$ & $2014 \mathrm{Y}$ & $2015 \mathrm{Y}$ & Total \\
\hline$<5 \mathrm{YR}$ & $62 \%$ & $61 \%$ & $76 \%$ & $76 \%$ & $72 \%$ & $69 \%$ & 555 \\
$5+\mathrm{YR}$ & $38 \%$ & $39 \%$ & $24 \%$ & $24 \%$ & $28 \%$ & $31 \%$ & 233 \\
\hline
\end{tabular}




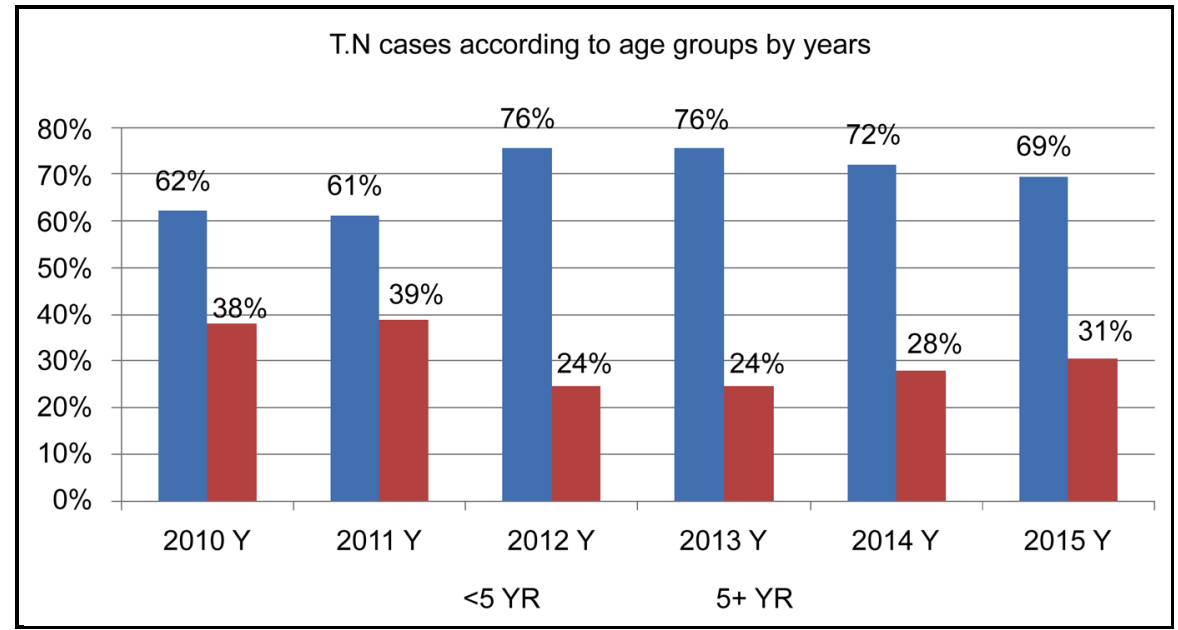

Figure 2. TIN cases percentage related to age; less than 5 years and 5 - 15 years old in all Governorates of Yemen from 2010-2015.

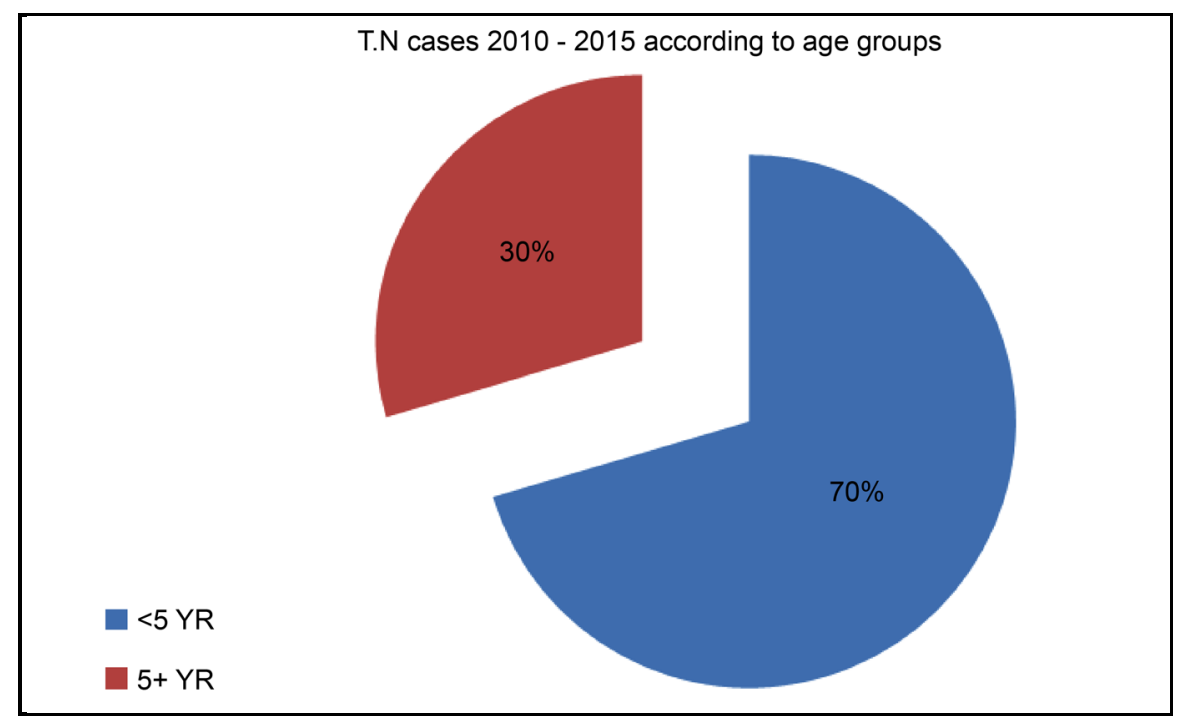

Figure 3. TIN cases percentage $<5$ years and $>5$ years old ( 5 - 15 years).

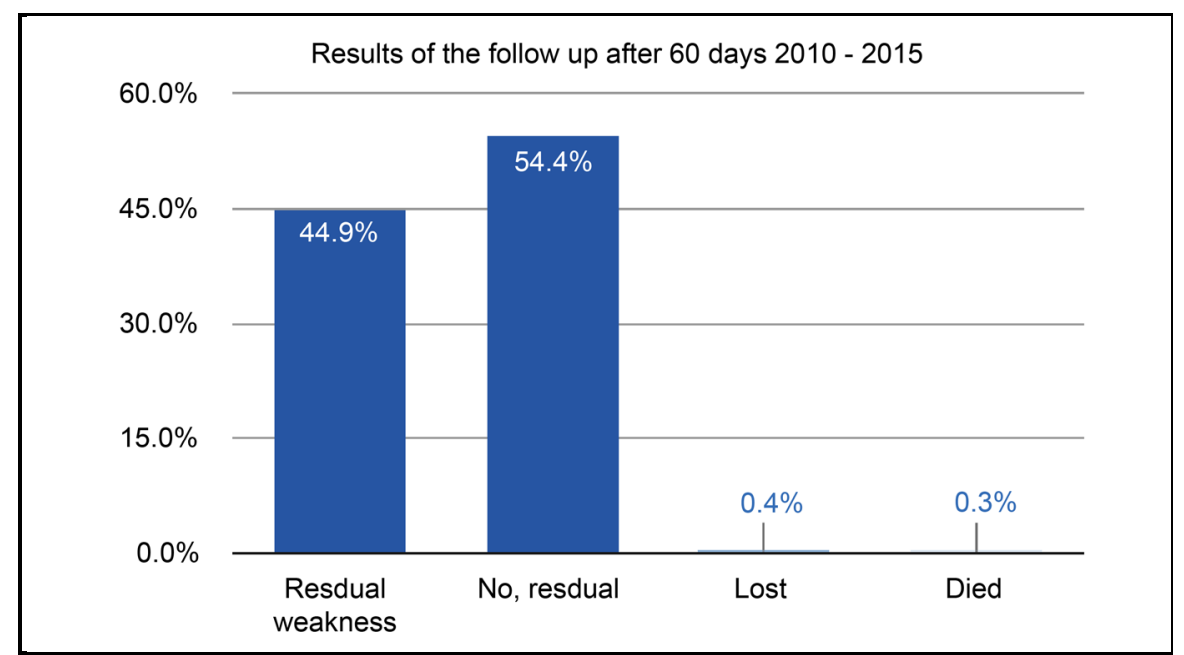

Figure 4. TIN cases percentage of Residual, Non-residual paralysis, Lost and Died. 
becoming more apparent. As we found 788 (TIN) cases, which now emerged as one of the most common cause of acute flaccid paralysis in Yemen in children under the age of 15 years after Guillain-Barré syndrome [8].

Most of the affected patients were males (67.1\%) males and (32.9\%) females, with similar result found in a study in Pakistan [9].

The predominance of males in the results is unexplained but may reflect the greater priority for health care given to boys over girls, which may be related to the culture behaviors.

Most of the cases (70.4\%) were less than 5 years old and (29.5\%) of cases 5 15 years old, which revealed the severity of this problem in children below 5 years, which can be explained due to receiving immunization at the gluteal region, and children at this age group are at high risk of infection.

In supporting to our study, a study carried in Pakistan found similar problem is particularly severe in children under the age of 1 year who suffer from a higher complication rate from injection methods, inappropriate for this age group [9].

Other study in Nigeria found children below the age of five years constituted more than two thirds (84.7\%) of the cases and males were more than females [10].

Children are more often affected than adults because less fat pad and lack of muscle bulk relative to adults and are more prone to sciatic nerve injury [1] [11] [12] [13].

In a review done by Mishra et al. 2010 reported 1506 sciatic nerve injuries of which $80 \%$ were affected in childhood [12].

In our study (54.4\%) TIN patients improved and (44.9\%) not improved in all Governorates in Yemen. The high number of not improved patients reflects the more severity of injury in children and inappropriate management and care after the injury, which is also found in Pakistan, as the residual paralysis 60 days after the onset of paralysis and was more common in children below 1 year of age than in older children [9].

Also the high percentage of not improved cases found in Iranian study, which concluded the high possibility of sciatic nerve injury is due to gluteal injection and its poor recovery in children [14].

In Yemen, it is observed that many untrained, unlicensed practitioners give these injections with inappropriate and unsafe injection practices.

\section{Conclusion}

Traumatic injection neuritis is the second most common cause of Acute Flaccid Paralysis in Yemen after Guillain-Barré Syndrome with high morbidity in children.

\section{Recommendation}

1) More awareness about TIN in the medical and para-medical staff as:

- Traumatic injection neuritis is a preventable complication of intramuscular injection. 
- Total avoidance of such injections is desirable, but if an intramuscular injection is essential, use of an appropriate administrative technique is crucial.

- If any TIN is suspected, immediate and optimal injury management can reduce neurological sequel and maximize the likelihood of recovery.

2) Further research using electrophysiology for assuring diagnosis of TIN and to predict the prognosis by follow-up.

\section{Acknowledgements}

Great thanks to the AFP program in Ministry of health Sanaa Capital of Yemen under the supervision of WHO, mainly the general director and all staff health workers for the supplement of data and statistics.

\section{References}

[1] Bramhall, R.J. and Deveraj, V.S. (2011) Traumatic Sciatic Nerve Palsy after Gluteal Injection. European Journal of Plastic Surgery, 34, 137-138. https://doi.org/10.1007/s00238-010-0533-2

[2] Halsey, N.A. (2003) Commentary: Poliomyelitis and Unnecessary Injections. International Journal of Epidemiology, 32, 278-279. https://doi.org/10.1093/ije/dyg071

[3] Miller, M.A. and Pisani, E. (1999) The Cost of Unsafe Injections. Bulletin of the World Health Organization, 77, 808-810.

[4] Eser, F., Aktekin, L.A., Bodur, H. and Atan, C. (2009) Etiological Factors of Traumatic Peripheral Nerve Injuries. Neurology India, 57, 434-437. https://doi.org/10.4103/0028-3886.55614

[5] Mansoor, F. (2004) Case Definition of Traumatic Injection Neuropathy. Pakistan Journal of Medical Research, 43, 143-149.

[6] Agha, A.A. and Shah, S.S. (2001) Unnecessary Therapeutic Injections: A Cause of Physical Disability. Infectious Disease Journal of Pakistan, 10, 22-23.

[7] Lagunju, I.A. and Okafor, O.O. (2009) An Analysis of Disorders Seen at the Paediatric Neurology Clinic, University College Hospital, Ibadan, Nigeria. West African Journal of Medicine, 28, 326-330. https://doi.org/10.4314/wajm.v28i1.48424

[8] Mujlli, H.M., Al-Kubati, A.S., Mojali, A.M. and Abdurab, A.M. (2016) Epidemiology of Childhood Guillain Barré Syndrome in Yemen. Open Access Library Journal, 3, e2425. https://doi.org/10.4236/oalib.1102425

[9] Mansoor, F., Hamid, S., Mir, T., Abdul Hafiz, R. and Mounts, A. (2005) Incidence of Traumatic Injection Neuropathy among Children in Pakistan. Eastern Mediterranean Health Journal, 11, 798.

[10] Alonge, I.A.O. and Akinwola, M.O. (2010) Post-Injection Sciatic Neuropathy: A Five-Year Review of Cases Managed in a Paediatric Hospital in Ibadan, Nigeria. AJPARS, 2, 10-13. https://doi.org/10.4314/ajprs.v2i1.62600

[11] Bağiş, S., Adam, M., Leblebici, Ü.B., Karataş, M., Güven, A.Z. and Çeliker, A.R. (2012) Sciatic Nerve Injury due to Intramuscular Injection: Electrophysiological Findings and One-Year Follow-Up. Turkish Journal of Medical Sciences, 42, 913 917.

[12] Mishra, P. and Stringer, M.D. (2010) Sciatic Nerve Injury from Intramuscular Injection: A Persistent and Global Problem. International Journal of Clinical Practice, 64, 1573-1579. https://doi.org/10.1111/j.1742-1241.2009.02177.x

[13] Fapojuwo, O.A., Akinlade, T.S. and Gbiri, C.A. (2008) A Three-Year Review of 
Sciatic Nerve Injection Palsy in the Physiotherapy Department of a Nigerian Specialist Hospital. African Journal of Medicine \& Medical Sciences, 37, 389-393.

[14] Toopchizadeh, V., Barzegar, M. and Habibzadeh, A. (2015) Sciatic Nerve Injection Palsy in Children, Electrophysiologic Pattern and Outcome: A Case Series Study. Iranian Journal of Child Neurology, 9, 69-72.

Submit or recommend next manuscript to OALib Journal and we will provide best service for you:

- Publication frequency: Monthly

- 9 subject areas of science, technology and medicine

- Fair and rigorous peer-review system

- Fast publication process

- Article promotion in various social networking sites (LinkedIn, Facebook, Twitter, etc.)

- Maximum dissemination of your research work

Submit Your Paper Online: Click Here to Submit

Or Contact service@oalib.com 